\title{
LA DISTRIBUCIÓN DE LOS CINISMOS EN LA NARRATIVA DE LEONARDO PADURA
}

\author{
POR \\ CARlos VAn TONGEREN \\ Manchester University
}

El cinismo es un tema de reflexión que aflora con frecuencia en la narrativa de Leonardo Padura Fuentes. La palabra cinismo como tal tiene una notable visibilidad en toda su narrativa, generando vínculos entre varios de los contextos históricos que el escritor ha abordado en su literatura. No resultan tan diferentes el policía Mario Conde y su grupo de amigos que protagonizan la saga policial "Las cuatro estaciones", o los agentes del aparato estalinista que aparecen en la novela más reciente El hombre que amaba a los perros (2009), en el momento de expresarse sobre lo cínico, sobre las dificultades de sobrevivir de cara a una ideología oficial en la que no creen y sobre la tensa situación en que uno no puede o quiere declarar en público lo que opina en privado.

No son escasos tampoco los estudiosos de la cultura cubana desde los años 90 que hagan mención del término cinismo en el marco de reflexiones más amplias sobre el desencanto, la reticencia, la indiferencia y la incertidumbre. En un artículo sobre el arte cubano de la década de los noventa, el hispanista Kevin Power hace un comentario sobre artistas como Ezequiel Suárez y Sandra Ceballos en que la obra de Padura se hace muy reconocible. Según Power, estos artistas

espouse irony rather than radical commitment, laconic observation rather than any faith in themselves as elements of change [...] they move comfortably within life's complexity and contradictions, and they don't feel responsible for sorting out the mess. Their responsibility is to find an adequate response to being alive. (56)

José Quiroga, por otra parte, afirma específicamente sobre la obra de Padura que sus personajes despliegan una suerte de "acid nonchalance" con respecto al sórdido y violento mundo en el que viven. Para Quiroga, esa negligencia no es solo un código de comportamiento procedente del cine noir norteamericano, sino también seña de una profunda melancolía específicamente relacionada con el desencanto generalizado con la Revolución cubana (20). Desde otra perspectiva, Guillermina De Ferrari identifica la presencia de un "cynical realism" en las distintas artes cubanas que circulan por 
el mercado globalizado. Recorriendo un conjunto variopinto de instalaciones, obras fotográficas y textos literarios, la crítica identifica en todos ellos la presencia de un hiperrealismo vanguardista, que muestra la realidad de maneras crudas y directas, participando de formas metacríticas en la fascinación internacional por la diferencia de lo cubano (175). Odette Casamayor-Cisneros, finalmente, examina la literatura de Pedro Juan Gutiérrez en términos parecidos a los que emplean Quiroga y De Ferrari en sus respectivos estudios. Para Casamayor-Cisneros, el cinismo emerge desde la obra de Gutiérrez como la única estrategia de supervivencia disponible frente a una realidad caótica; una postura ante la vida que, sin embargo, no dejaría de estar atormentada por sentimientos de culpabilidad, amor y compasión. Pero tales sentimientos, presentes todavía en la producción de Gutiérrez, acabarían desapareciendo en otros autores -Ena Lucía Portela, Wendy Guerra o Gerardo Fernández Fe- cuyos personajes despliegan posturas de radical indiferencia frente a su presente (262-63). La estudiosa cubana acuña en este contexto el concepto de "ingravidez ética", una postura posmoderna que se manifiesta como una indiferencia radical frente a los ideales de la modernidad (19-21) y que encontraría un antecedente ejemplar en una conocida frase de Milan Kundera, procedente de su novela La insoportable levedad del ser (1984): "Todo está perdonado de antemano y, por tanto, todo cínicamente permitido" (19).

El cinismo, así pues, se convierte en un parámetro descriptivo esencial para la forma en que distintos artistas cubanos contemporáneos se han acercado a su pasado y presente. Pero reconocer esto todavía no nos permite aclarar de qué maneras el cinismo podría diferenciarse de otros muchos de los términos que suelen aducirse como improntas del desencanto en la cultura y el arte cubanos. El presente ensayo pretende hacer un recorrido por varias tematizaciones del cinismo en la narrativa de Padura, con el objetivo doble de especificar los sentidos del cinismo para la producción literaria del cubano y de ampliar el alcance del valor analítico del término.

Para ello, anclaré el siguiente análisis en la famosa Crítica de la razón cínica (1983) de Peter Sloterdijk. En este estudio en dos tomos, Sloterdijk caracteriza el cinismo moderno como una "falsa conciencia ilustrada", marcada por una "fisura" que le permite al sujeto moderno proclamar una ideología sin creer en ella, o denunciar y al mismo tiempo perpetuar la decadencia y la corrupción (Kritik 225). Un concepto más antiguo en el que el cinismo moderno se origina es el quinismo, proveniente de la antigua doctrina de los Cínicos, protagonizada por Diógenes de Sinope y defensora de un uso escandaloso del cuerpo para desenmascarar la norma dominante. La diferencia entre el cinismo y el quinismo, tal y como queda sintetizada en uno de los capítulos que Sloterdijk dedica a los cinismos cardinales, estriba en sus respectivos grados de cercanía con respecto al poder estatal. Si el quinismo es una expresión de resistencia frente al orden político por parte de los oprimidos, el cinismo les pertenece más bien a los miembros de ese mismo orden político. Estos, si bien son capaces de reconocer

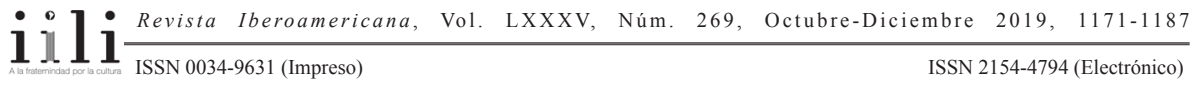


la veracidad de la crítica que les va dirigida desde las bajas esferas de la sociedad, no dejan de continuar con la opresión (400). En la óptica de Sloterdijk, el quinismo deviene político a la hora de encarar esa situación; es decir, es político porque se sitúa críticamente frente al poder y porque nace de los sujetos que deben sobrevivir a la defensiva (425) de cara a una esfera política en la que no creen. Para Sloterdijk, es en esta actitud crítica frente al orden dominante que el sujeto quínico va a seguir encontrando cierta autonomía: su conciencia sería una conciencia oprimida que no deja de ser parcialmente soberana [unterdrückt-souveränen Bewusstsein] (425). ${ }^{1}$

De este modo, la separación entre el quinismo y el cinismo puede ser esquematizada a partir de una división topográfica entre dos esferas: entre los que están abajo y los que están arriba (401). Sin embargo, lejos de tratarse de una oposición estable, la actitud quínica frente al poder puede convertirse en cinismo conforme se vaya deshaciendo de su situación periférica. Sloterdijk aporta un ejemplo histórico de este proceso: la progresiva legislación del cristianismo durante el imperio romano, después de que esta religión hubiera sido durante siglos una suerte de provocación quínica de toda forma mundana de poder (431-32). No obstante, el cristianismo encerraba ya un sentido cínico incluso antes de convertirse en la religión oficial del imperio, agrega Sloterdijk. Al plantear la eternidad divina como una alternativa frente a los poderes terrestres, la religión cristiana no solo sería una provocación quínica de estos, sino también una creencia cínica, practicada desde la altura de un sistema, o sea, desde la fe en la existencia de un poder supremo (428).

Ahora bien, si la división entre las esferas alta y baja inicialmente nos permitía dibujar un límite entre el cinismo y el quinismo, esta división amenaza con ser desdibujada por el adjetivo compuesto de lo quínico-cínico, empleado por Sloterdijk para dar cuenta de la doble cara del cristianismo descrita líneas arriba. Así, la diferencia entre el cinismo y el quinismo se revela como variable, dependiente del modo en que se prefiera poner de relieve la inclinación del cinismo hacia sus vertientes provocadora y opresora. Podría decirse que la relación entre lo cínico y lo quínico depende de lo que Jacques Rancière llamaría una peculiar distribución de lo sensible: una distribución de lugares, papeles y posiciones en una comunidad que incluye a unos y excluye a otros (Disagreement 28-29). Para Rancière, este proceso de distribución se lleva a cabo

\footnotetext{
Esta soberanía o autonomía de la consciencia cínica se liga con frecuencia a una separación entre los dominios público y privado (Sloterdijk, Kritik 700). Alexei Yurchak, en un estudio antropológico sobre el cinismo en la Unión Soviética tardía, aporta una serie de matizaciones sobre la medida en que los sujetos pueden gozar de pequeños momentos de privacidad aun cuando están inmersos en una celebración pública en la que actúan formalmente para apoyar la ideología dominante. Veáse también el trabajo de De Ferrari, quien, elaborando un argumento de Rafael Rojas, analiza la duplicidad de los intelectuales cubanos hoy y su compleja negociación entre posturas en público y en privado respecto a la Revolución (17-20).
}

$111 \frac{\text { Revista Iberoamericana, Vol. LXXXV, Núm. 269, Octubre-Diciembre 2019, }}{1171-1187}$ 
desde el orden policial; desde la ley que opera como "an order of the visible and the sayable that sees that a particular activity is visible and another is not, that this speech is understood as discourse and another as noise" (29). La política, en cambio, es para Rancière una actividad que interrumpe y reconfigura los papeles de las distintas partes de una comunidad, tal y como habían quedado distribuidos por la policía. Dicho de otro modo, Rancière reserva el término de la política para

an extremely determined activity antagonistic to policing: whatever breaks with the tangible configuration whereby parties and parts or lack of them are defined by a presupposition that, by definition, has no place in that configuration-that of the part of those who have no part. This break is manifest in a series of actions that reconfigure the space where parties, parts, or lack of parts have been defined. (29-30)

Partiendo de esta lectura conjunta de Sloterdijk y Rancière, este artículo emprenderá un análisis de la distribución de los cinismos en la obra narrativa de Leonardo Padura. Propongo realizar un seguimiento de las maneras en que su narrativa hace legibles las diferencias entre distintos tipos de cinismo y quinismo, así como de la medida en que las referencias al cinismo en su obra novelística se hacen dependientes de una distribución entre la esfera del poder oficial y la esfera privada, entre culpables y víctimas, y entre lo alto y lo bajo. Las estructuras narrativas de los distintos volúmenes de Padura serán de gran importancia a este respecto, ya que ayudan a revelar, visibilizar y hacer audibles los motivos de distintos personajes por actuar cínicamente, convirtiendo tal comportamiento en parte de una norma o bien en un desvío de la misma. Depende pues mucho de los rasgos narrativos particulares de cada obra si todo está perdonado de antemano y cínicamente permitido; y sobre todo, si este perdón y este permiso, referidos en la frase ya citada de Kundera, valen para todos en la narrativa de Padura.

\section{Quínicos y Cínicos en el Ciclo Mario Conde}

En los distintos volúmenes del ciclo de novelas protagonizado por el policía Mario Conde, el cinismo representa una serie de prácticas y posturas muy diversas. Si en ocasiones apunta a una actitud descreída de un personaje determinado frente a las opiniones y los valores propagados por los demás, en otros momentos el cinismo representa una relación conflictiva entre acciones y valores que se manifiesta al interior de un solo individuo. Una clave para abordar estas diferencias de forma más sistemática puede tomarse del papel que los distintos personajes cínicos cumplen con respecto a la investigación policiaca; es decir, si son sujetos u objetos de la pesquisa o bien si cumplen un papel marginal con respecto a la misma.

El propio protagonista de la serie es objeto de acusaciones de cinismo en diversas ocasiones. Los amigos del policía le acusan de una actitud cínica tanto en el segundo

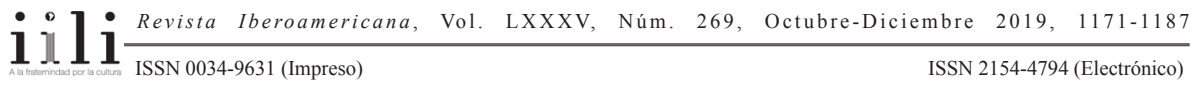


volumen, Vientos de cuaresma (1994), como en la cuarta novela Paisaje de otoño (1998) $(63,64,170)$. Un personaje llamado Candito el Rojo se desempeña con frecuencia como el informante del policía, gracias a su conocimiento profundizado sobre los submundos de la delincuencia en la capital cubana. En Vientos de cuaresma, Candito se molesta ante el hecho de que Mario Conde se interese más por la información que su amigo le puede brindar que por la amistad propiamente dicha $(82,83)$. El cinismo del policía, cabe entender, reside en que él mantiene su amistad con Candito a pesar de no concebir el valor de la relación más allá del beneficio propio. Al mismo tiempo, esta postura cínica dirige hacia un conflicto más amplio sobre las distintas filosofías de vida que circulan por el grupo de amistades de Mario Conde, sobre todo en lo que respecta a la fe que cada uno de ellos mantiene frente al futuro de la sociedad cubana. Candito el Rojo, por ejemplo, es un católico practicante, mientras que Mario Conde está alejado de cualquier tipo de creencia. El primero sigue apoyando un sistema de valores como parte de su fe en Dios, mientras que esta creencia está ausente por completo en Mario Conde y otros cubanos. La neblina del ayer (2005), una novela más tardía en la que Conde se ha retirado del cuerpo de la policía habanera para dedicarse a la compraventa de libros de segunda mano, ilustra esta diferencia ejemplarmente en el momento en que Mario Conde reconoce que si antes era "agnóstico", ahora se ha vuelto un "descreído" por completo (286).

La neblina del ayer contiene una emblemática reflexión sobre el momento histórico que le tocó vivir a la generación de Mario Conde. El policía se pregunta por qué existen en Cuba "tantos cínicos que juran por una cosa y creen en otra" (199). Su amigo el Conejo, que es historiador, acuña en su respuesta un concepto que para él está a la base no solo del cinismo, sino también de los deseos de la población cubana de encontrar una salida de la isla: “-Yo tengo un nombre para eso -retomó la batuta el historiador del grupo-: cansancio histórico. De tanto vivir lo excepcional, lo histórico, lo trascendente, la gente se cansa y quiere la normalidad. Como no la encuentran, la buscan por el camino de la anormalidad" (199). Según el historiador, el cinismo debe interpretarse como seña de desencanto y cansancio con la obligada responsabilidad de ser "buenos a la fuerza" (178). A partir de la reflexión del historiador, el cinismo generalizado al que Mario Conde se refiere adquiere un fuerte sentido quínico, emergiendo como una actitud de resistencia frente al proyecto socialista, es decir, un intento de reivindicar una alternativa frente a la obligada necesidad de que las acciones personales constituyan un eslabón en el camino hacia el futuro utópico. Renunciar a ese telos, o cansarse de él, es un impulso quínico que en las obras de Padura cuenta con una presencia amplia en todo el entramado social. El propio de Conde atestigua la existencia de diferentes tipos de cinismo y reconoce que el cansancio histórico no le parece su expresión más problemática: "Los que más me joden no son ésos -reflexionó el Conde-. Los que me enferman son los que quieren parecer perfectos, confiables, pero que son todos unos 
oportunistas de mierda" (199). El comentario puede ampliarse hacia la actitud del propio policía, que si bien es denunciada en ocasiones como cínica, no llega a ser percibida como la manifestación del mismo oportunismo tramposo que queda denunciado en La neblina del ayer.

Otros volúmenes del ciclo policial plantean una interpretación semejante sobre el cinismo, caracterizándolo como una estrategia de preservación que responde ante las condiciones materiales de la vida en la Cuba de los noventa. El narrador de la última novela de "Las cuatro estaciones", Paisaje de otoño, caracteriza el cinismo de Mario Conde como el "anticuerpo que le permitía seguir con su vida" y enfrentarse a diario con un mundo marcado por el crimen y la corrupción (163). De manera parecida, se caracteriza a un alumno del Preuniversitario donde ocurrió el asesinato Vientos de cuaresma: si bien Mario Conde está tentado a denunciar el "cinismo" del joven, que no se atreve a "decir la verdad", Carlos el Flaco le explica que el estudiante meramente está reproduciendo "la ley de la selva" (127). Y en un crudo retrato de la vida en el Barrio Chino de La Habana en La neblina del ayer, explica el narrador que las nefastas condiciones en las que viven los habitantes de la zona "solía[n] tornarlos agresivos y cínicos" (138). Ser cínico es, en todos estos casos, hacer gala de una actitud curtida, requerida para poder seguir haciendo frente a una dificultosa circunstancia social e histórica. Hay una gran similitud entre el retrato del cinismo que ofrece Padura y lo que Manuel Vázquez Montalbán, en su Crónica sentimental de España (1971), ha llamado "una filosofía de la vida cínica, en el sentido no insultante de la palabra, si es que esta palabra puede ser para nuestra sentimentalidad un insulto" (37). El comentario de Vázquez Montalbán forma parte de un análisis de una serie de canciones populares que se cantaban con frecuencia en la España de la posguerra ("Que no me quiero enterar" de Conchita Piquer o el "Rascayú" de Bonet de San Pedro). Al cantar estas letras, afirma Vázquez Montalbán, la sociedad española de los primeros años de la dictadura franquista expresaba "su derecho a no comprender del todo las cosas y hacer de esa profesión del absurdo una extrema declaración de lucidez" (36). En las canciones analizadas por Vázquez Montalbán, esta postura cínica se manifiesta concretamente como una delimitación de la propia conciencia; los sujetos cínicos se aferran a los sueños para evitar enfrentamientos directos con experiencias dolorosas (Piquer, "Que no me quiero enterar"), o bien cuestionan con ironía a un hombre que todas las noches visita la tumba de su mujer para perpetuar sus lazos afectivos con ella (“¿Rascayú, cuando mueras qué harás tú?”). Traduciendo esta filosofía popular a los fragmentos de la obra de Padura que hemos examinado hasta ahora, cabe observar que en ambos contextos el cinismo se percibe como una renuncia a comportamientos ejemplares impuestos, compartida a gran escala en un ámbito popular de la sociedad.

Muy diferentes son, sin embargo, las referencias al cinismo de los personajes que se convierten en víctimas de un asesinato en la primera y la cuarta novela de "Las

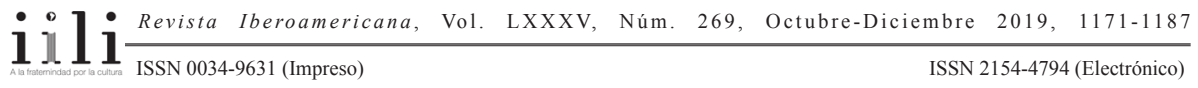


cuatro estaciones". En Pasado perfecto (1991), el volumen que abre la serie, aparece asesinado un personaje llamado Rafael Morín, un antiguo conocido de Mario Conde que, a diferencia de éste, siempre había obedecido ejemplarmente las normas de la educación bajo el sistema castrista. No sorprende, entonces, que Morín pudiera asentarse cómodamente en el sistema, afiliarse al Ministerio de Industrias y enriquecerse a través de varias empresas. En la novela, sin embargo, Morín muere accidentalmente en una pelea con uno de los socios que le ayudó a desviar parte de los fondos del ministerio cubano hacia el Banco Vizcaya.

A lo largo de Pasado perfecto continuamente se llama la atención sobre el carácter tramposo de Rafael Morín, y también la conclusión que el policía formula sobre la víctima es claramente acusatoria: "Aquel hombre era un apestado en más de un sentido" (226). Aun así, un amigo de Mario Conde llamado Miki Cara de Jeva aporta una reflexión pertinente para situar el comportamiento de Rafael Morín a la luz del de Mario Conde y otros cubanos. Morín rompió y volvió a sellar su amistad con Miki Cara de Jeva, un escritor resentido que trabaja para el régimen, en función de la seguridad de su propia posición dentro del Partido Comunista. Con todo, Miki afirma que Morín no dejó de ser un "oportunista elegante", a diferencia de Conde que "también [es] un jodido", pero sin gozar de la misma capacidad de autocrítica que Morín: "No vas a ser nada, Conde, porque quieres juzgar a todo el mundo y no te juzgas nunca a ti mismo" (156). Esta reflexión permitiría relacionar el cinismo de Morín con la actitud del protagonista y de otros personajes que generalmente quedan exonerados de una crítica moral sostenida en estas novelas. Con todo, Pasado perfecto no lleva a cabo una verdadera problematización del límite entre las respectivas posturas cínicas de Morín, Conde y otros. Prueba de ello es el final de la obra, donde se restablece la barrera entre Conde y su viejo rival a partir de su acceso radicalmente dispar al apoyo de una colectividad. El policía asiste al entierro de Morín, destacando la ausencia de la mujer de la víctima así como de todos los viejos amigos de este durante la ceremonia. De este modo, se refuerza la impresión de que Morín y Conde son dos figuras radicalmente distintas: el primero carece por completo del círculo de amistades con el que Conde sí puede contar, tanto cuando acude en la casa de su amigo Carlos el Flaco al volver del entierro en las páginas finales de Pasado perfecto, como en las reuniones amistosas a la que acudirá en todos los volúmenes futuros de la serie (Ferrari 41-51).

En Paisaje de otoño, el cuarto volumen de la serie, Mario Conde debe investigar las prácticas oscuras de un grupo de oficiales vinculados al Departamento Estatal de Bienes Expropiados. El primero de ellos es Guillermo Gómez de la Peña, ex director de Planificación y Economía que durante la primera fase de la Revolución cubana, en el marco de la expropiación de los bienes de la burguesía cubana, pudo adueñarse de la famosa pintura de Henri Matisse que da título a la novela. Gómez de la Peña se regocija en el capital simbólico que le brinda la posesión del cuadro y se expresa sin 
reparos sobre la comodidad de la casa de la que se ha apropiado. Por ello, el policía caracteriza a Gómez de la Peña como un "experto en cinismo" (46). En fases posteriores de la novela, "[s] u oportunismo blindado y su cinismo casi invencible" (144) no tardan en convertirse en actitudes plenamente ridículas, puesto que la obra de Matisse resulta ser una copia que le fue vendida bajo pretextos falsos por su socio Miguel Forcade, el antiguo jefe del Departamento de Bienes Expropiados que trató de llevarse el cuadro original fuera de Cuba para hacer un buen negocio con la venta. A Conde se le presenta la tarea de investigar la muerte de Forcade, cuyo cadáver castrado ha sido arrojado por el mar en la Playa del Chivo, en una zona infecta y llena de suciedad que apunta desde el comienzo a las prácticas delictivas en que Forcade ha participado (29-30).

El asesino resulta ser un viejo conocido de Forcade llamado Adrián Riverón. Riverón es el primero en denunciar la "cara cínica" de la víctima (159). Al final de la novela, el detective se pone de acuerdo con el asesino y varias personas más sobre el hecho de que la muerte de Forcade se debe a las jugadas tramposas de este con "todas las posibilidades depravadas del poder" (144). Conde denuncia las injusticias que "los Forcade, los Gómez, los Bodes" habían sido capaces de perpetrar desde "arriba" (144). Miriam Forcade, hermana de la víctima, ni siquiera siente lástima por la muerte de su hermano y se lamenta más bien por el hecho de que ella y su novio no hayan conseguido salir de Cuba (162). Y el padre de Forcade, en un comentario alegórico sobre la flora de su jardín, concluye que la fuerza de la que sí gozan sus árboles le faltó a su hijo: "Sobreviven los más fuertes y los más hábiles. Los demás se van a la mierda, teniente" (167). En esta novela, la investigación detectivesca termina una vez que se haya restablecido un consenso rotundo sobre el hecho de que Forcade se ha buscado su propia muerte. Más que una víctima, este último se convierte en la víctima culpable de la trama.

De tal forma, tanto Pasado perfecto como Paisaje de otoño realizan lo que Sloterdijk define como un análisis del cinismo in nuce (Kritik 557). Según Sloterdijk, la pesquisa policial tradicionalmente pone de manifiesto la difusa frontera entre un acto que jurídicamente ha sido reconocido como un crimen, y otras transgresiones morales que dentro del sistema jurídico pueden seguir siendo impunes. Así por ejemplo, si bien el delincuente es culpable de asesinatos u otros "delitos propiamente dichos", Sloterdijk recalca que el transgresor no de por sí es peor que la víctima, quien suele haber pecado a su vez de "cinismos, inmoralidades impunes" (Crítica 449). Sloterdijk concluye por ello que la víctima, al no haber respetado los códigos morales que el detective todavía representa y defiende, de alguna manera se ha buscado su propia muerte (449). ${ }^{2}$

En su estudio sobre el género policial en España, Joan Ramon Resina reflexiona en términos sumamente parecidos a los de Sloterdijk sobre la figura de la víctima (El cadáver 68).

$111 \frac{\text { Revista Iberoamericana, Vol. LXXXV, Núm. 269, Octubre-Diciembre 2019, } 1171-1187}{\text { ISSN 2154-4794 (Electrónico) }}$ 
En Paisaje de otoño, igual que en Pasado perfecto, el policía y los familiares de los muertos ayudan con sus respectivos testimonios a culpabilizar a las víctimas y, así, a realizar una simbólica "expulsión” de estas. Para Joan Ramon Resina, la identificación de un culpable, para su posterior expulsión de la novela, hace que el universo ficcional quede purificado de la violencia que antes amenazaba con disgregar el orden:

El interés intrínseco -y para algunos adictivo- del género no estriba tanto en la averiguación de las circunstancias de la muerte -las celebres preguntas ¿quién?, ¿dónde?, ¿cuándo?-, cuanto en la reiteración -con todas las variantes posibles- de un ritual cuya finalidad consiste en impedir el contagio y expulsar la violencia; que consiste, en definitiva, en restablecer la cohesión moral de la sociedad, ubicando la violencia en un culpable. ("La novela policiaca" 36)

En la obra de Padura, la asignación de culpas no sucede mediante la ubicación de violencia física en las figuras de Morín y Forcade, pero sí claramente a través de la formulación de acusaciones sobre sus respectivas caras cínicas. Y si bien estas novelas no pretenden restablecer un orden social depurado, es innegable que sí mantienen en pie una aspiración al consenso sobre los orígenes de la violencia y sobre el hecho de que estos deben buscarse principalmente en las esferas sociales y políticas situadas arriba. En este contexto, es significativo que al principio de Paisaje de otoño se describa con lujo de detalles la apariencia física del cadáver de Forcade, con mención de la "crueldad" y la "venganza profunda" que quedan patentes a partir de la brutal mutilación de su cuerpo (29-30). De esta manera, se anuncia desde una fase temprana de la obra, que la expulsión del culpable, su conversión en cadáver, debe ser comprendida como una reacción a una transgresión anteriormente cometida por el mismo muerto.

El asesinato no deja de ser en ambas novelas un obstáculo: impide la realización de un cuestionamiento de la privilegiada posición de Morín, Forcade y otros clanes poderosos. En estas obras, las perspectivas de Morín y Forcade pueden ser reconstruidas solamente a partir de los testimonios y opiniones que sobre estos personajes comparten sus familiares y conocidos; y como hemos visto, son sobre todo las opiniones menos favorables las que más visibilidad tienen en los textos. Si estas novelas contienen los gérmenes de un análisis de las distintas manifestaciones del cinismo en la Cuba de los noventa, una pregunta que dejan sin respuesta es hasta qué punto el cinismo perpetrado desde arriba por la cúpula del régimen podría parecerse al impulso quínico de los oprimidos y derrotados, a cuyas perspectivas las novelas de Padura brindan un acceso mucho más amplio.

Según Resina, el misterio básico del género policial no reside en el acertijo cerebral que debe ser resuelto por la figura detectivesca. Por el contrario, el núcleo del misterio policial se hallaría en el "rito con el cual se expulsa la violencia que amenaza

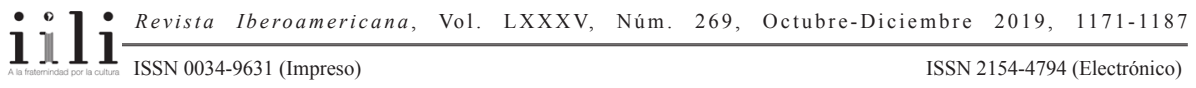


con extenderse por todo el cuerpo social" ("La novela policiaca" 36). ${ }^{3} \mathrm{Si}$ el género policial en buena medida simula todas las certezas que proclama, determinando una serie de causas para la violencia que pueden ser "reales o ilusorias" $(35,36)$, entonces el modo en que estas causas se "ubican" en determinado lugar de la sociedad puede caracterizarse como una operación policial en el estricto sentido que Rancière otorga a este último término: como una asignación de posiciones y papeles desde donde se hacen legibles e interpretables tanto las similitudes como las diferencias entre los distintos personajes implicados en el caso criminal. En este sentido, podría decirse que en "Las cuatro estaciones" solapan dos sentidos de lo policial: las novelas corresponden con el sello genérico aplicado a la investigación literaria de un crimen, pero también hacen gala de un proceso de distribución de lugares, posiciones y fronteras que nos permite distinguir con claridad entre los quinismos y cinismos de Conde, Morín, Forcade y otros. A continuación, con nuestra lectura de otra obra más reciente de Padura, habrá ocasión para problematizar la aparente claridad de este proceso de distribución.

\section{LOS AGENTES QUíNICO-CínICOS DEL ESTALINISMO EN EL HOMBRE QUE AMABA A LOS PERROS}

El hombre que amaba a los perros, vasta novela que entremezcla claves del género policial y de la novela histórica, pone en escena distintos acercamientos entre personajes inicialmente opuestos. Los paralelismos más evidentes son aquellos que existen entre los personajes centrales de los tres ejes narrativos de la obra: León Trotski, líder bolchevique que fue expulsado de la Unión Soviética de Stalin y asesinado posteriormente en Coyoacán; Ramón Mercader, reclutado en España para asesinar a Trotski; y el veterinario cubano Iván Cárdenas, que pasea sus perros en una playa cubana y empieza a encontrarse cíclicamente con un hombre desconocido, identificado más adelante como un Ramón Mercader ya más viejo. Si las historias de Trotski, Mercader y Cárdenas se enlazan a partir de su desencanto compartido con distintos episodios de la historia revolucionaria del siglo XX, el penúltimo capítulo del volumen escenifica una serie de encuentros muy relevantes entre Mercader y su antiguo mentor soviético Leonid Eitington o Kotov. A lo largo de este capítulo, víctimas y victimarios cambian de lugar continuamente, configurando así un interesante juego de posiciones que se hace legible, además, como un verdadero "tratado" sobre el cinismo. ${ }^{4}$

3 Resina remite en su análisis a la filosofía de René Girard. En su Violence and the Sacred (1972), el filósofo francés caracteriza la creación de una víctima sucedánea a quien se le asigna la responsabilidad para toda la violencia que se produce en una comunidad, como una ilusión o mistificación que recorre todas las sociedades (Girard 81-82).

4 Palabras de Leonardo Padura en una conversación personal con el autor, La Habana, UNEAC, 6 de junio de 2013.

$111 \frac{\text { Revista Iberoamericana, Vol. LXXXV, Núm. 269, Octubre-Diciembre 2019, } 1171-1187}{\text { ISSN 2154-4794 (Electrónico) }}$ 
El encuentro entre Mercader y su antiguo superior sucede en Moscú en agosto de 1968, casi tres décadas después del asesinato de Trotski y en los días justamente posteriores a la invasión soviética en Checoslovaquia. Bajo este telón de fondo histórico, que impregna la acción con un sentimiento generalizado de derrota, Ramón Mercader se enfrenta a una traición de lo que durante décadas había sido su utopía personal: poder contar con el apoyo de los miembros del aparato estalinista, y sobre todo de su mentor personal, para poder evitar un largo encierro en la cárcel de Lecumberri. La conversación con su antiguo mentor le enseña que su vida nunca le importó a nadie; que Stalin y su cúpula deseaban que él muriera en el acto de matar a Trotski; y que la carta que llevaba consigo para quedarse absuelto de una persecución jurídica en México había sido llenada concienzudamente con mentiras por Kotov (El hombre 703).

En este contexto, cabe leer sistemáticamente las numerosas referencias al cinismo en el capítulo. Ya en 1940, el abogado mexicano de Mercader había observado que la carta de Kotov no había sido escrita sino por "un cínico con el mayor desprecio por la inteligencia, pues sabía que esas mentiras iban a ser descubiertas en diez minutos" (676). Mercader, por su parte, también debe sostener varias mentiras sobre su identidad frente a su abogado y otros implicados en el juicio. Pero hay una diferencia de estatus importante entre las mentiras enunciadas por Mercader y las de su superior. A fin de cuentas, el primero se ha convertido en el partido de defensa en un proceso jurídico, mientras que Kotov ha difundido una serie de mentiras que comprometen negativamente a su subordinado. De este modo, en esta fase de la narración solo la actitud de Kotov se hace legible como realmente cínica, puesto que él no está sujeto a las consecuencias jurídicas de la mentira.

Con todo, el penúltimo capítulo de El hombre que amaba de los perros paulatinamente va complejizando el trasfondo de las acciones de Kotov. El texto busca multiplicar los puntos de vista desde los que observar, comprender y juzgar las trayectorias tanto de Mercader como de su antiguo mentor. Por un lado, el capítulo pretende plasmar una mirada retrospectiva sobre lo sucedido. Esto lo ilustra el epígrafe de Juan 9 del Nuevo Testamento, que contrapone la ceguera del pasado con la capacidad de la vista en el presente. Ver a Kotov y "saber" la verdad oculta sobre el pasado también es lo que desea Mercader tras recibir la llamada telefónica de su antiguo mentor (677). Podría parecer, entonces, que los personajes hablan como historiadores y no como actores en lo sucedido (Ponte, "El asesino"). Un ejemplo de esta óptica historiográfica aparece cuando Mercader evoca con extrañeza el amor hacia Stalin que Kotov siempre le quiso inculcar: “[...] siempre que penetraba en aquellos pantanos, Ramón se sentía desubicado, como si le hablaran de una historia ajena a la suya, de una realidad diferente a la que él mismo había creado en su cabeza" (687).

Pero, por otro lado, no es que la distancia temporal les haya brindado a estos personajes una posición estable con respecto a las operaciones que realizaron durante

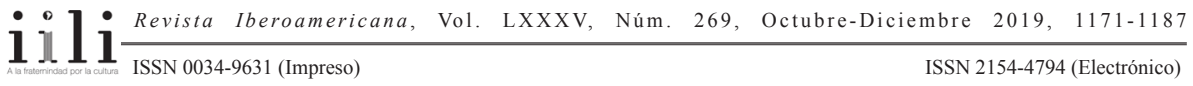


los presuntos tiempos de ceguera. Sus lugares de enunciación están continuamente a caballo entre el pasado y el presente. Esto lo ilustra ejemplarmente el juego con los diferentes nombres que ambos han usado a lo largo de sus respectivas carreras (689). Al dirigirse a su antiguo mentor, Mercader suele emplear el nombre actual de este -Lionel, Lionia o Leonid Eitington-. No obstante, en algunas de las ocasiones en que el último toma la palabra, se restaura igualmente su nombre anterior (689).

Tanto Mercader como Kotov transitan en este capítulo entre grados muy distintos de responsabilidad e influencia activa sobre sus actos en el pasado. La primera parte del capítulo insiste en que Mercader debe ser visto como una víctima, que ha sufrido la historia y que carece de responsabilidades últimas. Así por ejemplo, Mercader reflexiona para sus adentros que no ha operado sino como un "brazo" en la trama (679), armado por un "cerebro" externo a él y más poderoso que él. Esta idea también la verbaliza el policía mexicano Leandro Sánchez Salazar durante una de las primeras interrogaciones: “¿Qué cerebro armó su brazo?” (674). También la voz narrativa advierte que "gracias a una macabra confluencia" se confundieron los destinos de Mercader y Trotski (683) y recalca que Mercader ha estado sujeto continuamente a fuerzas históricas decididamente mayores (697).

Las acciones de Mercader se subyugan no solo al peso del desarrollo histórico, sino igualmente a la fuerza y voluntad del maestro. "Hasta el nombre me debes, Ramón" le dice Kotov, que inventó el apellido actualmente usado por su discípulo (Ramón Pavlovich) (681). Inicialmente, a Ramón le cueste asumir las verdades “demasiado cínicas" sobre el pasado que su antiguo mentor comparte con él (704). Esto indica que, en esta fase temprana, la iniciación de Ramón en una realidad ya plenamente conocida y asumida por su mentor todavía no ha sido completada.

La barrera entre Mercader y Kotov también se manifiesta en un plano afectivo, o sea, a partir de la emisión de sonidos y miradas por parte del mentor que impactan en el cuerpo del otro personaje. Un primer ejemplo de ello es la mirada de Kotov: hay un extraño brillo en los ojos de mentor que a Mercader le hace dudar de la veracidad de sus palabras (689-90). Una segunda manifestación afectiva de la diferencia entre ambos estriba en las risas del mentor. Durante su primer encuentro en una taberna, Kotov ya había emitido unas risas "sonoras y guturales" que a Ramón le trasladaban a "los viejos tiempos" (681). Durante el segundo encuentro con su antiguo alumno, Kotov se ríe de nuevo "estruendosamente" tras bromear que seguramente ha mantenido un aspecto más joven que los otros por estar "embalsamado en cinismo" (701). Es relevante que la altura y el timbre peculiar de estas risas le pertenezcan únicamente a Kotov. Mercader no se ríe en ningún momento durante este ciclo de conversaciones y el capítulo solo recoge el recuerdo de una risa de Ramón, emitida durante su conversación con los terapeutas mexicanos que le diagnosticaron un complejo de Edipo (739).

Esto nos dirige de nuevo al estudio de Sloterdijk, particularmente a su catálogo de expresiones psicosomáticas de cinismo, donde aparece igualmente un detallado análisis

$111 \frac{\text { Revista Iberoamericana, Vol. LXXXV, Núm. 269, Octubre-Diciembre 2019, } 1171-1187}{\text { ISSN 2154-4794 (Electrónico) }}$ 
de distintos tipos de risas. Al cinismo señorial (Herrenzynismus), dice Sloterdijk, le corresponde una risa torcida que visualiza la escisión de la conciencia del poderoso: una parte de la boca "sabe en efecto que en el fondo no hay nada de qué reírse" (Crítica 230). "Ésta es la sonrisa en el nivel del poder y de su melancolía tal y como aparece en altos funcionarios, políticos y redactores" (230). O sea, el cínico se ríe "de una manera melancólica y despectiva", desde la altura del poder y desde su correspondiente carencia de ilusiones (Illusionslosigkeit) (Crítica 231; Kritik 275). Por otro lado, el quínico se reiría de una forma animalesca, total; en su caso, la risa es energía pura, no amortiguada por ningún tipo de reservas y en la que no quedan restos de ningún ego. Es una risa estruendosa, carcajeante y fanfarrona (231).

Frente a esta comparación de distintas muecas cínicas y quínicas -desde la boca semicerrada y torcida hacia la risa estruendosa- cabe retener también la tipología desarrollada por Simon Critchley de los distintos timbres y alturas de la risa. En sus ensayos "Comedy and Finitude: Displacing the Tragic-Heroic Paradigm in Philosophy and Psychoanalysis", recogido en su Ethics-Politics-Subjectivity (1999), y On Humour (2002), Critchley avanza una interpretación de la comicidad en contraposición al término de la tragedia. Cada uno de estos dos paradigmas -el cómico y el trágicopresentaría un acercamiento filosófico diferente a la finitud del ser humano: mientras que la tragedia opera como una afirmación de la finitud, la comicidad sería más bien su reconocimiento (On Humour 102). ¿Cómo distinguir entre una afirmación (trágica) y un reconocimiento (cómico) de la finitud? Para aclarar esa diferencia, Critchley recurre a una analogía espacial: las risas trágica y cómica se harían distinguibles a partir de las respectivas alturas desde las cuales estallan. Es decir, si la risa trágica suena "from the mountain tops, a manic laughter: solitary, hysterical, verging on sobbing" ("Comedy" 113-14; énfasis en original), la risa cómica tendría en cambio un carácter débil, razón por la cual en palabras de Critchley esta última risa "arises out of a palpable sense of inability, inauthenticity, impossibility", siendo al mismo tiempo "more joyful (not to mention being a lot funnier), and also more tragic" (114). ${ }^{5}$

Pues bien, si la tipología de Sloterdijk nos invita a identificar a Kotov con la risa total y sin reservas del sujeto quínico, Critchley nos llevaría a caracterizar la risa estruendosa del mentor soviético como una afirmación trágica de la finitud, mucho menos cómica y melancólica que la risa débil que se manifiesta desde abajo. Leídas en conjunto, ambas perspectivas teóricas indican que el volumen y timbre de la risa de Kotov puede tener implicaciones muy diversas. Para Mercader, en todo caso, la risa

5 En su Infinitely Demanding: Ethics of Commitment, Politics of Resistance (2007), Critchley reproduce gran parte de estas reflexiones en una lectura detenida del texto "Der Humor" de Sigmund Freud (7782). En la última parte del libro, Critchley agrega lo siguiente sobre la fuerza política que desde su óptica posee el humor: "Politically, humour is a powerless power that uses its position of weakness to expose those in power through forms of self-aware ridicule" (124).

$111 \frac{\text { Revista Iberoamericana, Vol. LXXXV, Núm. 269, Octubre-Diciembre 2019, }}{1171-1187}$ 
de su mentor es una señal auditiva que lo asienta firmemente en su papel durante el pasado. Sin embargo, haciéndonos eco de Sloterdijk, tal vez haya también un dejo de quinismo en la risa de Kotov. En otros términos, sería posible identificarla no solamente como una risa histérica que emana desde una altura solitaria, sino también como fruto de una entrega total desde abajo.

Conforme vaya avanzando el capítulo de El hombre que amaba a los perros, aparecerán varios paralelismos entre mentor y alumno que confirman en doble carácter quínico-cínico de Kotov. El cuestionamiento de la diferencia entre los personajes sucede en ambas direcciones. Por una parte, Mercader va a reconocerse afín al papel desempeñado por su mentor en la historia. Así por ejemplo, Mercader recuerda la incómoda sensación que le provocó la lectura de una carta del político Nikolai Bujarin, "A una futura generación de dirigentes del Partido", que según Ramón fue pensada para los "verdugos" del aparato estalinista: "debía de estar mirando a Ramón, a Kotov, a otros como ellos" (689). Kotov, por su parte, no tiene reparos en incorporar a su alumno en el grupo de "apestados" (692) al que cree que ambos pertenecen. Cuando la palabra "cínicos" sale por primera vez de la boca de Kotov (695), también es con referencia a ambos. Y más adelante, también Mercader deja constancia de su oscilación entre diferentes perspectivas al reconocerse al mismo tiempo "cínico" y "marioneta" el día que mató a Trotski (707).

Un hecho que aleja al mentor de su papel anterior es que ya no forma parte del sistema en la actualidad de las conversaciones (682). Acaba de salir de la cárcel, donde fue encerrado por otros miembros de la cúpula soviética que después de la muerte de Stalin continuaron con la ya muy notoria cultura de persecuciones y purgas. Por motivo de su encierro, Kotov se considera parte en el presente de un grupo más amplio de personas derrotadas y traicionadas por el desvío dictatorial de la utopía socialista. Así, cuando Mercader se lamenta por el hecho de haber sido "una marioneta, un infeliz que tenía fe y creyó lo que tipos como [Kotov] y Caridad le dijeron", añade Kotov: "Muchacho, a todos nos engañaron" (707). Los verdaderos culpables del engaño son Ellos, palabra que en la novela se imprime en itálicas y que Mercader y Kotov repiten uno tras otro en su conversación. El término se deja leer como una representación abstracta de la cúpula estalinista de la que ambos personajes, en esta fase de sus vidas, claramente se distancian (683).

Kotov, entonces, se mueve en este capítulo entre las perspectivas del sujeto quínico, que ha procurado sobrevivir en una cultura de miedo, purgas y persecuciones, y otra postura que le permite evaluar los sucesos desde la privilegiada posición de una "atalaya del cinismo" (720). En este contexto, no deja de ser notable que Kotov, que se reconoce como un sujeto que ha sido engañado, critique la ingenuidad de su antiguo discípulo. El mentor afirma que Mercader pudo haber sabido desde el principio que se le estaba mintiendo. También se burla de los arrepentimientos ensayados por Mercader: "no me venga con historias" es su respuesta cuando Mercader afirma que tal vez hubiera

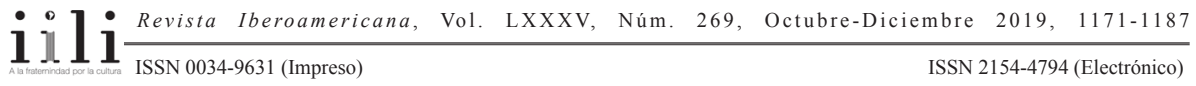


dejado de implicarse en el asesinato de Trotski si primero se hubiera leído sus obras (707). Así pues, si bien Kotov dice ser un derrotado como Mercader, por momentos sigue ascendiendo al lugar privilegiado de la sabiduría histórica, permitiéndose unas últimas palabras de juicio sobre lo que, en su óptica, han sido los errores de su alumno.

Después de una compleja trayectoria de fluctuaciones entre el cinismo y quinismo, el capítulo termina sin embargo con un acto de nivelación y comprensión mutua. Durante una de las últimas cenas narradas en el libro, los personajes comen, beben y cantan juntos. A Ramón, este encuentro le lleva a reflexionar que a pesar de todo valía la pena vivir y que Eitington era la "demostración exultante de aquella certeza" (737). Agrega que el "cinismo" de Eitington, "a prueba de golpes y años de cárcel, resultaba salvador y paradigmático"; y finalmente, tras preguntarse "¿Y no era él tan cínico como su mentor?" (737), responde afirmativamente que él tampoco quiere evadir responsabilidades (737).

Cabe concluir, a partir de este último fragmento, que no son dos figuras señoriales las que se encuentran en este capítulo, sino dos figuras derrotadas o, según la ilustrativa palabra que Ramón enuncia en catalán al final del capítulo: fantasmes. Los personajes no se reúnen en los espaciosos salones y atalayas del poder, sino en el comedor casero de un apartamento de hormigón. Dicho de otro modo, se reúnen de la misma forma en que lo hacen cíclicamente los amigos de Mario Conde, sujeto cada uno a su propias dolencias físicas y filosóficas, de las que tratan de liberarse por momentos escuchando canciones - preferentemente, como es harto sabido por los lectores asiduos de Padura, "Proud Mary" de Creedence Clearwater Revival-, devorando cenas abundantes y riéndose a carcajadas hasta más no poder.

La existencia de este paralelismo entre El hombre que amaba a los perros y las novelas protagonizadas por Mario Conde, no quiere decir que Padura convierta a todos sus personajes en los mismos "pobres diablos" (Ponte). Tanto Mercader como Kotov hacen gala de una multitud de identidades; sus vidas están marcadas por un sinfín de caídas y ascensiones (Fornet 388) que, en su conjunto, complejizan la fijación de un solo papel para ellos. Ambos agentes acaban reconociéndose cómplices y endeudados con las esferas alta y baja. Kotov, sobre todo, baja por momentos de su atalaya para introducirse en un ámbito cotidiano y manifestar su cara quínica.

Así, en estas páginas de El hombre que amaba a los perros Padura realiza una búsqueda de esa "palabra común" (Rancière, La división) entre sujetos normalmente destinados a ocupar posiciones antagónicas en el terreno de lo policial. Si los límites entre Conde, Morín, Forcade y otros personajes se dibujaban con claridad, El hombre que amaba a los perros demuestra que la línea entre el cinismo de los opresores y el quinismo de los oprimidos, que ya vertebraba "Las cuatro estaciones" y otras novelas de Padura, puede convertirse en materia para una compleja investigación policial e historiográfica. Si nos hacemos partícipes de la mirada alegórica que Padura suele plasmar sobre diferentes épocas históricas y contextos culturales, los impulsos quínico-

$111 \frac{\text { Revista Iberoamericana, Vol. LXXXV, Núm. 269, Octubre-Diciembre 2019, }}{1171-1187}$ 
cínicos que esta novela descubre en la tardía Unión Soviética pueden convertirse en un tema de reflexión igual de válido para el mundo de hoy.

\section{BiBLIOGRAFÍA}

Casamayor-Cisneros, Odette. Utopía, distopía e ingravidez. Reconfiguraciones cosmológicas en la narrativa postsoviética cubana. Madrid/Frankfurt: Iberoamericana/Vervuert, 2013.

Critchley, Simon. "Comedy and Finitude: Displacing the Tragic-Heroic Paradigm in Philosophy and Psychoanalysis." Ethics-Politics-Subjectivity. Nueva York: Verso, 1999. 217-38.

Infinitely Demanding: Ethics of Commitment, Politics of Resistance. Nueva York: Verso, 2007.

On Humour. Nueva York: Routledge, 2002.

Ferrari, Guillermina de. Community and Culture in Post-Soviet Cuba. Nueva York: Routledge, 2014.

Fornet, Jorge. "Elogio de la incertidumbre. Cuba novelada en el siglo XXI". Revista Iberoamericana 79.243 (2013): 371-94.

Freud, Sigmund. "Der Humor." 1927. Der Witz und seinen Beziehung zum Unbewußten. Der Humor. Frankfurt am Main: Fischer, 2012. 253-58.

Girard, René. Violence and the Sacred. Patrick Gregory, trad. Baltimore: Johns Hopkins UP, 1977.

Padura Fuentes, Leonardo. El hombre que amaba a los perros. Barcelona: Tusquets, 2011. La neblina del ayer. Barcelona: Tusquets, 2009.

Paisaje de otoño. Barcelona: Tusquets, 2009.

Pasado perfecto. Barcelona: Tusquets, 2000.

Vientos de cuaresma. Barcelona: Tusquets, 2001.

Ponte, Antonio José. "El asesino de Trotski, en una feria de La Habana". Diario de Cuba, 28 de marzo 2011. <http://www.diariodecuba.com/cultura/1301305237_1883. html $>14$ sept. 2015.

Power, Kevin. "Cuba: One Story after Another." While Cuba Waits: Arts from the Nineties. Nueva York: Smart Art Press, 1999. 23-65.

Quiroga, José. Cuban Palimpsests. Minneapolis: U of Minnesota P, 2005.

Rancière, Jacques. Disagreement: Politics and Philosophy. Julie Rose, trad. Minneapolis: U of Minnesota P, 1999.

La división de lo sensible: política y estética. Antonio Fernández Lera, trad. Salamanca: Centro de Arte de Salamanca, 2002.

Resina, Joan Ramon. El cadáver en la cocina. La novela criminal en la cultura del desencanto. Barcelona: Anthropos, 1997. 
"La novela policíaca como exorcismo". Indicios, señales y narraciones. Literatura policíaca en lengua española. Enrique Rodrigues-Moura, ed. Innsbruck: Innsbruck UP, 2010. 35-45.

Sloterdijk, Peter. Crítica de la razón cínica. Miguel Ángel Vega, trad. Madrid: Siruela, 2003.

Kritik der zynischen Vernunft. Frankfurt: Suhrkamp, 1983.

Vázquez Montalbán, Manuel. Crónica sentimental de España. Barcelona: Planeta, 2003. Yurchak, Alexei. “The Cynical Reason of Late Socialism: Power, Pretense, and the Anekdot." Public Culture 9/2 (1997): 161-88.

Palabras clave: $\quad$ cinismo - quinismo - risa - novela policial - política

Recibido: $\quad$ agosto 2016

Aceptado: $\quad$ mayo 2017 
